\title{
A COMPARATIVE STUDY OF THE EFFECTS OF THE NEUROCOGNITIVE-BASED MODEL AND THE CONVENTIONAL MODEL ON LEARNER ATTENTION, WORKING MEMORY AND MOOD
}

\author{
${ }^{1}$ Sanit Srikoon, ${ }^{2}$ Tassanee Bunterm, ${ }^{3}$ Teerachai Nethanomsak \\ \& ${ }^{4}$ Tang Keow Ngang \\ ${ }^{1-3}$ Faculty of Education \\ ${ }^{4}$ International College \\ Khon Kaen University, Khon Kaen,Thailand
}

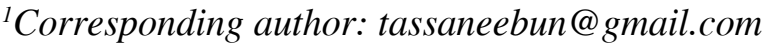

\begin{abstract}
Purpose - The attention, working memory, and mood of learners are the most important abilities in the learning process. This study was concerned with the comparison of contextualized attention, working memory, and mood through a neurocognitive-based model (5P) and a conventional model (5E). It sought to examine the significant change in attention, working memory, and mood of Grade 9 students after the intervention of a neurocognitive-based model (5P) and a conventional model (5E) in an experimental group and a control group, respectively.

Methodology - A total of 76 out of 324 Grade 9 students were randomly selected from a high school located in Mahasarakham province, Thailand. A pre-test and post-test control group design was employed. The neurocognitive-based model (5P) was developed utilizing a neurocognitive-based theory and was implemented in the experiment group, while the conventional model (5E) was used in the control group. Three types of psychological tests were utilized as research instruments, namely the attention computerized battery test, the working memory computerized battery test, and the BondLadder visual analogue scale. MANOVA analysis was used to analyse the effect of these instructional models on student attention, working memory, and mood.
\end{abstract}


Findings - The findings revealed that the overall attention, working memory, and mood conditioning mean score of the neurocognitivebased model (5P) interventions were better than in the conventional model. In conclusion, neurocognitive-based contextualization had more effect on the attention, working memory, and mood of Grade 9 students than conventional model (5E) contextualization.

Significance - The findings contribute significantly to current knowledge on the effectiveness of the neurocognitive-based model (5P) to enhance student learning outcomes in terms of attention, working memory and mood.

Keywords: Neurocognitive-based model (5P), conventional model (5E), attention,working memory, mood.

\section{INTRODUCTION}

Attention is the means by which learners actively process a limited amount of information from the enormous amount of information available through our senses, our stored memories, and our other cognitive processes (Rao, 2003). It includes both conscious and unconscious processes. In many cases, conscious processes are relatively easy to study. Unconscious processes are more difficult to study, simply because learners are not conscious of them (Merikle, 2000). Attention allows learners to use their limited mental resources judiciously. By dimming the lights against many stimuli from outside (sensations) and inside (thoughts and memories), learners can highlight the stimuli that interest them. This heightened focus increases the likelihood that learners can respond speedily and accurately to interesting stimuli. Heightened attention also paves the way for memory processes. Learners are more likely to remember information which they have paid attention to and not information they have ignored (Sternberg, 2012).

According to Cowan (2012), working memory is the small amount of information kept in the mind at any time. It is needed for various types of learning: comprehension, problem-solving, and goaldirected thinking. The working memory capabilities of learners 
grow with maturity, and educational practices should be based on an understanding of both the limitations and the educational possibilities. Educational principles are proposed to make the most of working memory for optimal learning throughout development. In short, the working memory is an active system of storing information and information processing, and is essential for the correct functioning of other complex cognitive functions (SanchezTorres, Elosua, Lorente-Omenaca, Moreno-Izco \& Cuesta, 2015).

Mood is defined as the understanding of how the brain processes emotions, whether they are negative or positive, and how that functioning influences learner capacity to attend to, perceive, and remember information. Mood is a kind of emotion process whereby multiple areas of the brain are engaged. The brain's emotional responses in the learner begin with the limbic system, which has been most widely recognized as the brain's emotional centre (Gazzaniga, Ivry \& Mangun, 2009). The amygdala is engaged, not only in implicit emotional reaction, such as an unexpected fearful event, but also in explicit emotional learning, such as learning about a danger and remembering the information (Hardiman, 2012).

The above arguments clearly indicate that attention, working memory and mood are related and important in student learning. Working memory and attention are related because the process of attention has its beginning when the brain remembers what the senses capture (Sternberg, 2012; Gazzaniga et al., 2009). Attention must be based on prior knowledge of the elements and learning is usually associated with memory (Cowan, 2012). In fact, the process involves mood and memory and, of course, both processes require attention. In short, an effective teaching model should be designed to ultimately keep learner attention, which is the foundation for memory and information (Sanchez-Torres et al., 2015). This is why an understanding of how the brain receives and saves information will help teachers to make informed choices for effective teaching models.

\section{AIMS OF THE STUDY}

This study sought to explore the effect of using the neurocognitivebased model (5P), an instructional model on attention, working memory, and mood. It was the main study undertaken after the 
researchers had conducted a pilot study to develop the neurocognitivebased model (5P), a model which combined research-based learning and educational neuroscience approaches to the understanding of the learning phenomenon in educational instruction. The neurocognitive-based model (5P) was verified by nine experts before it was utilized in the actual study. More specifically, this study was aimed at achieving the following objectives:

i. To identify the attention of Grade 9 students in terms of accuracy and reaction time before and after utilizing the neurocognitive-based model (5P) (experimental group) and conventional model (5E) (control group), respectively.

ii. To study the differences in attention, accuracy and reaction time between the learners in the experimental group and the control group.

iii. To identify the working memory of Grade 9 students in terms of accuracy and reaction time before and after utilizing the neurocognitive-based model (5P) and the conventional model (5E), respectively.

iv. To study the differences in working memory accuracy and reaction time between the learners in the experimental group and the control group.

v. To identify the mood of Grade 9 students in terms of alertness, calmness, and contentedness before and after utilizing the neurocognitive-based model (5P) and the conventional model (5E), respectively.

vi. To study the differences in mood between the learners in the experimental group and the control group.

\section{CONCEPTUAL FRAMEWORK}

This study was concerned with determining the learning outcomes of two instructional models, namely the neurocognitive-based model (5P) and the conventional model (5E). The learning outcomes were measured in terms of attention, working memory, and mood. All instructional models provided the opportunity for teacher and students to learn how the students' knowledge, cognition, and emotions interact with the environment, and how both changes occurred through the learning process (Joyce, Weil \& Calhoun, 2015). Current thinking in educational neuroscience is synthesized 
to provide a perspective on modern learning theory and instruction models, especially in relation to some emerging ideas in relation to correlations and patterns in neurocognitive processing of information that focus on attention, working memory and mood for developing learners (Anderson, 2009). Moreover, a combination of research-based and neurocognitive-based learning can enhance the essential skills required in the twenty-first century (Bunterm, Lee, Ng, Srikoon, Vangpoomyai, Rattanavongsa \& Rachahoon, 2014). The neurocognitive-based model (5P) is an innovative instructional model which has integrated the two major components of researchbased learning and educational neuroscience (Srikoon, 2015). Therefore, the syntax of the neurocognitive-based model (5P) has integrated research-based learning activities with a focus on attention, working memory, and mood. The variables in this study are as elucidated in Figure 1.

\section{Neurocognitive-based Model (5P)}

Goswami (2008) highlighted in detail how the learner's brain built cognitive systems from his or her sensory memory. As a result, the researchers integrated educational neuroscience and research-based learning into the neurocognitive-based model (5P). According to Goswami and Szucs (2010), in order to build a cognitive system, such as language or conceptual knowledge from information gained by looking and listening, the learner's brain needed to focus on dynamic spatio-temporal structures. Learners are similar to interested agents that move about, and say and do things. The goal-directed actions of agents provide integrated dynamic multisensory information that can be attended to and stored by the brain. Therefore, the principle of the neurocognitive-based model $(5 \mathrm{P})$ is to promote learner development of attention, working memory, and positive mood.

Following this line of reasoning, learners are expected to generate better memory and attention and learn more about subject content during the research process. As a result, the neurocognitivebased model (5P) covers five main phases: persuasion, planning, performance, production, and presentation. In the persuasion stage, teachers investigate learners' prior knowledge. Learners study the principles of the research process based on research ethics, and 
analyse, train, and share the case study's research question. In the planning phase, learners are trained to devise their research plan and share it with their friends. In the performance stage, learners collect and analyse data, and in the production phase they are trained to interpret the results after analysing the data. The final phase is the presentation phase, in which the learners are asked to write their research reports and make presentations about the research process.

Anderson (2009) proposed the synthesis of the two emerging fields of neurocognitive learning theory and the constructivist philosophy of science teaching and learning to improve the attention of learners. The latter has already become a major guiding model for instructional design in many disciplines. Neurocognitive learning theory is a synthesis of three traditionally separate strands of inquiry: (i) Neurophysiology, with its emphasis on the biological bases of brain and neural activity; (ii) Cognitive science, with its focus on information processing and internal representations of experience, and (iii) Learning theory that explains how learners cumulatively interact with, and adapt to, their environment (Anderson, 2009).

When schools build an executive function culture across classrooms, they empower learners to learn 'how to learn' and 'how to solve problems flexibly'. These processes are critically important for working memory to succeed. When teachers foster the same emphasis on learning strategies, persistence and a strong work ethic are promoted, and these should lead to academic and life success. As learners learn effective approaches to enhance their work, their motivation, self-confidence, and resilience also increased (Meltzer, 2010).

In order to consider how teachers might address the emotional climate or mood in the classroom, teachers should have some understanding of how the brain processes emotions. According to Hardiman (2012), explicit emotional learning engaged the hippocampus, a key structure involved in memory, in addition to the amygdala. Learners may intuitively know that emotionally charged events stay in their memory. This relationship between emotion and memory is supported by research demonstrating that the engagement of the amygdala does indeed strengthen memory (Ferry, Roozendaal \& 
McGaugh, 1999). In other words, the involvement of the amygdala in declarative memories explains why learners remember emotionally charged events better than ordinary day-to-day occurrences.

\section{Conventional Model (5E)}

The conventional model $(5 \mathrm{E})$ is the instruction model used in the control group and is the normal approach to teaching in Thailand. This conventional model (5E) is supported by the Institute for the Promotion of Teaching Science and Technology (IPST) (2012) in the standard classroom in Thailand. The conventional model (5E) consists of five phases: engage, explore, explain, elaborate, and evaluate. The conventional model (5E) allows teachers and learners to experience common activities, build on prior knowledge and experience, construct meaning, and continually assess learner understanding of a concept.

In the engage phase, learners have to make connections between past and present learning experiences. Teachers anticipate activities and focus on learners' thinking in the learning outcomes. Learners become mentally engaged in the concept or skills to be learned. The explore phase of the conventional model (5E) provides learners with a common base of experiences. Learners actively explore their environment or manipulate materials to identify and develop concepts, processes, and skills.

In the explain phase, teachers help learners to explain the concepts the latter has explored in the previous phase. Learners have opportunities to verbalize their conceptual understanding or to demonstrate new skills or behaviours. On the other hand, teachers take opportunities to introduce formal terms, definitions, and explanations for concepts, processes, skills or behaviours. This is followed by the elaborate phase. Learners are encouraged to extend their conceptual understanding and practise their skills and behaviours. Learners develop a deeper and broader understanding of major concepts, obtain more information about areas of interests and refine their skills. The final phase of the conventional model (5E) is the evaluate phase. Learners are encouraged to assess their understanding and abilities, while teachers evaluate learners' understanding of key concepts and skills development. 


\section{Learning Outcomes: Attention, Working Memory, and Mood}

Attention is the most essential information process. It includes organizing information into a coherent structure and optimizing conceptual understanding (Mayer, Kim \& Park, 2011; Yang \& Chang, 2015). Attention is comprised of sustained attention, focus attention, selective attention, and divided attention. The process of attention begins with alertness, selected attention, and executive control (Sternberg, 2012). From the reviews of Sieb (1990) and Sternberg (2012), it can be concluded that the brain areas involved in attention are in the prefrontal association cortex (PAC). As a result of the PAC mechanisms, only one sensory stimulus activates the orientation, alerting, awareness, arousal, and cognitive systems and then, as a result, attention occurs. Attention influences working memory learning outcomes (Loaiza \& McCabe, 2013; Yang \& Chang, 2015).

Working memory is an active system of storing information and information processing. It is essential for the correct functioning of other complex cognitive functions (Jacob \& Silvanto, 2015; Sanchez-Torres et al., 2015). Baddeley and Hitch (1974) proposes a working memory model which consists of four components: the phonological loop, visual spatial sketchpad, episodic buffer, and central executive system. This system addresses executive functions such as performance of two tasks simultaneously (divided attention), selection of attention to a stimulus and interference in the inhibition of others, and updating of incoming information, as well as processing and maintaining information in the long-term memory (Baddeley, 2012).

The effect of mood on the learning process is taken into consideration because mood can enhance learners' information processing (Brandoni \& Anderson, 2009; Denning, 2013; Hardiman, 2012; Newton, 2013). Mood is seen as including: alertness (alertdrowsy, attentive-dreamy, lethargic-energetic, muzzy-clearheaded, coordinated-clumsy, mentally slow-quick witted, strong-feeble, interested-bored, incompetent-proficient), calmness (calm-excited, tense-relaxed), and contentedness (contented-discontented, troubledtranquil, happy-sad, antagonistic-friendly, withdrawn-sociable). 
Mood has been found to influence working memory (Anderson, 2009; Hardiman, 2012) and learners' learning (De Carolis \& Ferilli, 2014).

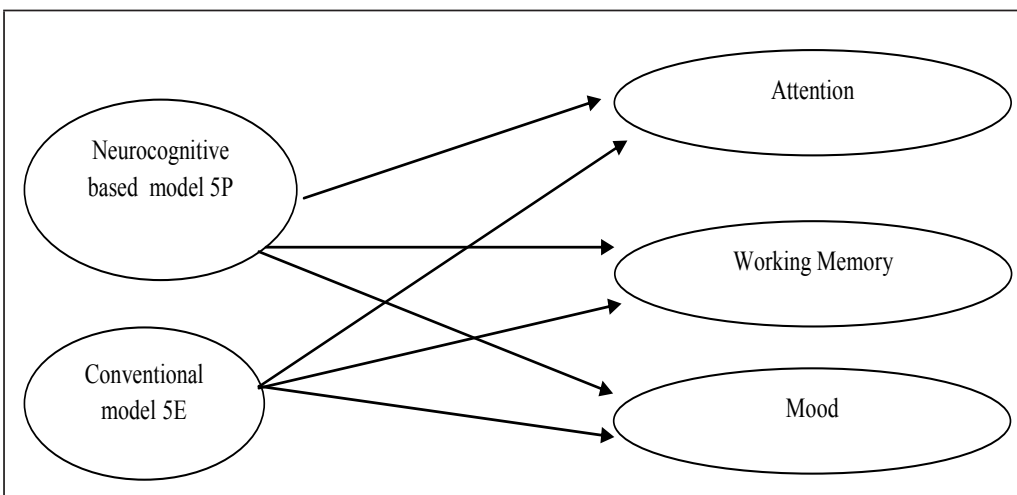

Figure 1. The effects of the neurocognitive-based model and conventional model on learner attention, working memory and mood

\section{METHODOLOGY OF THE STUDY}

\section{Research Design}

The researchers utilized a true experimental pre-test and posttest control group design. This design is especially useful in the evaluation of instructional models when there is more than one purposely created group, common measured outcomes and random assignment. It is also particularly suitable in addressing evaluation questions about the impact of instructional models because it emphasises the use of comparative data as the context for interpreting findings. Furthermore, this design can increase our confidence that the observed outcomes (attention, working memory and mood) are the result of the given instructional model or innovation, instead of being a function of extraneous variables.

In addition, with regard to the issue of the non-equivalent group, the pre-test post-test design will partially eliminate a major limitation of the non-equivalent group, post-test only design because the two groups (experimental group and control group) may not have been the 
same before any instruction took place, and may differ in important ways that could influence the observed outcomes. Therefore, if one group performed better than the other on the post-test, we could rule out initial differences (if the groups were in fact similar on the pretest) and normal development (e.g., resulting from the conventional instructional model) as explanations for the differences.

\section{Participants and Sampling Procedure}

Robust comparisons were possible through the use of a true experimental design in which students were randomly assigned to different instructional models and comparison groups. The sampling process began with random selection and was followed by random assignment. A total of 76 samples were randomly selected from 324 Grade 9 students in a high school located in the Mahasarakham province of Thailand during the second semester of the 2014 academic year. The selected samples were randomly distributed into two groups: experimental group (neurocognitive-based model, 5P: $n=38$ ) and control group (conventional model, 5E: $n=38$ ). The random assignment was accomplished by the flip of a coin.

Random selection is important for external validity. Therefore, the researchers would be able to use the results of this study to generalize to the larger population. Random assignment is central to internal validity, and has allowed the researchers to make causal claims about the effect of the intervention. The consequence of random selection and random assignment were clearly very different, and the strong research design that was employed helped to ensure both internal and external validity.

\section{Intervention Process}

A preliminary study was conducted to refine the intervention and to provide evidence of a manipulation check of the validity of the intervention. This preliminary study consisted of two phases. Firstly, researchers developed and validated the neurocognitivebased model (5P) and this was followed by conducting the full trial procedures. The preliminary study was aimed at maximizing the possibility that the intervention would be conducted successfully in the actual study. 
The 5P model was developed based on concepts from two major fields, namely educational neurosciences and research based instruction. After reviewing the literature related to educational neurosciences (Anderson, 2009; Dudukovic, Du Brow \& Wagner, 2009; Fredrickson \& Branigan, 2005; Sarter, Bruno \& Given, 2003) and research-based instruction (Pithiyanuwat \& Bunterm, 1994; Prasertsan, 2012a, 2012b; Suwanwela, 2008, Willison \& O'Regan, 2007), the researchers developed the first prototype of the 5P model. This was followed by a professional meeting with six experts from two different fields - three from the field of curriculum and instruction (two from Khon Kaen University and one from Udon Thani Rajabhat University) and the other three from the field of Educational Research, Measurement and Evaluation (two from Khon Kaen University and one from Mahasarakham University) in August 2013. Revisions were made based on the suggestions and feedback from the six experts. This was done in order to determine the intervention process for each step when utilizing the 5P model.

Next, the following three documents were developed to modify and improve the first prototype of the 5P model: (i) a synthesis of knowledge about research-based instruction and ways of integrating neuroscience knowledge in an educational setting; (ii) the second prototype of the 5P model and examples of lesson plans were created, and (iii) a teacher's guide on how to use the model. These three documents were evaluated and validated by nine experts from three major fields, namely science education, educational research and evaluation, and neurosciences. Finally, a meeting with each of the nine experts was carried out to evaluate the validity of the three documents in November, 2014. All the nine experts rated the proposed 5P model as good and excellent. Consequently, the 5P model developed in this way was ready to be piloted.

The proposed 5P model was piloted with a total of 34 Grade 9 students from a population of 179 in another school located in Mahasarakham province, Thailand in January 2015. The pilot study samples were selected based on their similar attributes to the actual study samples, for example their science achievement scores and school location. One of the researchers taught the topic of Biodiversity using the 5P model for a period of three hours, and two observers evaluated the student learning outcomes. The two 
observers were the head of a science department and a science teacher who has about 10 years of teaching experience in the pilot study school. The pretest-posttest design was administered to the pilot study sample. The two observers found that the intervention using the 5P model was reliable and good. After a manipulation check was carried out, the researchers started to conduct the actual study by measuring the learning outcomes of the two selected science classes in terms of their attention, working memory, and mood. Each class was presented with and taught an identical unit.

The experimental design used in the study was able to reveal the differences in learning outcomes in terms of attention, working memory, and mood, as hypothesized under the conditions of the two different instructional models (neurocognitive-based 5P or conventional 5E model.

The syntax of the 5P Model consisted of the following five steps: i) Persuasion: The teacher investigated the prior knowledge of students. Students studied the principles of the research process and the simple case study research based on research ethics. Students were trained to recall visualizations and experiences, speedily write up the problem situation and set the research question. Then, the students reviewed the literature, having been trained to organize ideas, use the connective system, and the mind map. ii) Planning: Students were trained to plan their strategies and analyse the case study with open-ended questions. Students undertook research planning and engaged in further research planning. The students presented their own research plans and shared it with the class. iii) Performance: Students were trained in ordering data, note taking techniques, the number-association system, and creative categorization. The students then collected data according to their own research plans. They analysed the research data and presented the findings to the class. iv) Production: Students were trained to give a presentation, develop a conclusion strategy, and analyse the case study. They have to conclude the results of their data analysis and present it to their classmates, and v) Presentation: Students were guided on the ethics of doing and presenting a research report. After the presentation, students shared their research experiences with their classmates. 
The conventional model was used to teach the control group. The syntax of the conventional model (5E) comprised the following steps. i) Engage: The lesson would begin with the introduction of the topic to be studied. The teacher asked the students to choose a specific topic and helped them to interact with the material; ii) Explore: The teacher would motivate the students to carry out experiments according to the proper laboratory manual procedures. The teacher described the procedure for the inquiry method and then prepared the apparatus for the students to perform the experiment and analyse the data; iii) Explain: The teacher asked the students to present the results of the experiment in front of the class; iv) Elaborate: The teacher asked the students to answer a prepared set of applied questions related directly to the topic of their previous investigation, and v) Evaluate: The teacher observed and took notes of the students' discussion, taking a special interest in how the students answered the questions, and how they conducted the actual experiment.

The pre-test and post-test measured outcomes in relation to attention, working memory, and mood before and after the intervention. The neurocognitive-based (5P) and conventional (5E) models were used to deliver instructions on the eco-system science content in the classrooms for three hours per week, over a total of six weeks. The neurocognitive-based model (5P) was used to instruct the experimental group while the conventional model (5E) was used to instruct the control group. The study was especially designed to compare the learning outcomes namely in relation to attention, working memory, and mood between the neurocognitive-based model (5P) and the conventional model (5E).

A major consideration in designing the experimental procedures was to ensure that they were not too disruptive of normal class procedures. A detailed plan on the implementation of the intervention process was provided to school principals before approval to conduct the experiment was obtained. The key researcher himself implemented both instructional models to both groups of students. In addition, it was important to clearly communicate the plan to additional instructors who could be involved with implementing the intervention. Weekly meetings with the principal, assistant principal, and heads of departments were used to ensure consistency 
in the experimental procedures between different classrooms. However, deviations from the plan were bound to occur during any intervention. Thus, it was important to maintain records of the actual implementation, in addition to the planned implementation. This information was useful for evaluating the results and explaining why they might or might not be as expected. Routinely reviewing implementation records during the intervention process provided the key researcher with the opportunity to overcome problems during the current intervention, or to refine the future intervention.

\section{Research Instruments}

Research instruments were mainly used as tests to measure learning outcomes. A total of three types of instruments were used to measure the attention, working memory, and mood of the students. Two sets of battery tests were utilized in this study: the attention battery test and the working memory battery test. These were used mainly to measure students' attention and working memory respectively. The attention battery test consisted of 14 sub-tests or 14 tasks covering: i) sr-sound; ii) sustain-sound; iii) select-ch- sound; iv) sr-letter Thai; v) focus- letter Thai; vi) sustain- letter Thai; vii) D20-select-chletter Thai; viii) E21-select-ch- letter Thai; ix) sr-dot; $x$ ) focus-dot; xi) sustain-dot; xii) D20-select-ch- dot; xiii) E21-select-ch- dot, and xiv) series Thai letter. The students were given 50 trials in each task. This attention battery test enabled the researchers to measure attention accuracy and reaction time. All the 14 sub-tests or tasks of the attention battery test were in the Thai language and the goodness of fit test for construct validity had been evaluated by Bunterm et al. (2015). Test-retest reliability values of these sub-tests ranged from 0.939 to 0.998 .

The working memory battery test comprised 13 tasks. Students were given 50 trials for the 10 tasks and 10 trials for the remaining three tasks. This working memory battery test covered: i) stroop; ii) flanker-arrow; iii) odd-even; iv) vowel-consonant; v) switch-Thai letter Number; vi) left-right; vii) up-down; viii) switch-up-downleft-right; ix) Thai word span; x) number updating; xi) 0-back; xii) 1-back, and xiii) 2-back. This working memory battery test enabled the researchers to measure working memory accuracy and reaction time. Again, all the 13 tasks of the working memory battery test 
were in the Thai language and the goodness of fit test for construct validity purpose had been evaluated by Bunterm et al. (2015). The test-retest reliability values of these tasks ranged from 0.822 to 0.979 .

The researchers used a 16-item Bond-Ladder visual analogue scale to assess mood factors such as alertness, calmness, and contentedness. This instrument had been translated from English to the Thai language by experts from the Department of Physiology, Faculty of Medicine, Khon Kaen University, Thailand. This BondLadder visual analogue scale was evaluated for construct validity by Srikoon (2015). The reliability (KR20) value was 0.888 .

The researchers investigated three major constructs which covered five factors, namely accuracy and reaction time of attention, accuracy and reaction time of working memory, and mood. Therefore, the data was analysed according to these five factors. Attention was defined as the most essential information process, which included organizing information into a coherent structure and optimizing conceptual understanding (Mayer, Kim \& Park, 2011; Yang \& Chang, 2015), and comprised sustained attention, focus attention, selective attention, and divided attention. Working memory was defined as an active system of storing information and information processing and was essential for the correct functioning of other complex cognitive functions (Jacob \& Silvanto, 2015; SanchezTorres et al., 2015). It comprised four components: phonological loop, visual spatial sketchpad, episodic buffer, and central executive system (Baddeley \& Hitch, 1974). Mood was referred to as alertness (alert-drowsy, attentive-dreamy, lethargic-energetic, muzzy-clearheaded, coordinated-clumsy, mentally slow-quick witted, strong-feeble, interested-bored, incompetent-proficient), calmness (calm-excited, tense-relaxed), and contentedness (contenteddiscontented, troubled-tranquil, happy-sad, antagonistic-friendly, withdrawn-sociable) and was found to influence working memory (Anderson, 2009; Hardiman, 2012) and learners' learning (De Carolis \& Ferilli, 2014). Working memory and attention were found to be associated with each other because the process of attention had its beginning when the brain remembered what the senses captured (Sternberg, 2012; Gazzaniga et al., 2009). Attention was developed 
based on prior knowledge of the elements (Cowan, 2012). It can therefore, be concluded that mood and memory are interrelated and both processes require attention.

Wilks' lambda is a test statistic used in the multivariate analysis of variance (MANOVA), nainly to test whether there are differences between the means of identified groups of subjects on a combination of dependent variables. In this study, the researchers tested whether the mean score of the two groups was the same across the five factors simultaneously. Thus, the researchers considered all dependent variables and compared the mean of this combination for the two groups. Wilks' lambda performs, in the multivariate setting, with a combination of dependent variables, the same role as the F-test performs in a one-way analysis of variance. Wilks' lambda is a direct measure of the proportion of variance in the combination of dependent variables that is unaccounted for in the group variable (Everitt \& Dunn, 1991).

\section{RESULTS}

The results of this study are presented in accordance with the research aims indicated above. The findings first discusses the differences in the attention, working memory and mood of Grade 9 students before and after using the neurocognitive-based (5P) and conventional $(5 \mathrm{E})$ models. This is followed by an evaluation of the impact of the neurocognitive-based (5P) and conventional (5E) models on Grade 9 students' attention, working memory and mood. Finally, the different impacts of the two instructional models are measured.

There were three test assumptions made for MANOVA and ANOVA, namely: i) observations must be independent, ii) the variance-covariance metric must be equal for all treatment groups, and iii) normal distribution (Hair, Black, Anderson \& Tatham, 2006). However when Box's $M$ test found that the covariance matrices were significantly different across the levels of the independent variables suggesting an increased possibility of Type 1 error, the researchers had to make a smaller error region. In this case, the researchers decided to use the significance level as 0.001 in order 
to solve the Type 1 error. Therefore, it was probably not a problem for the researchers to proceed although the second assumption was found to be not met.

\section{Findings on Attention}

Attention was measured based on attention accuracy and reaction time of attention (in milliseconds, ms). The mean score and standard deviation of attention accuracy and reaction time measured by each subtest between experimental group and control group is as shown in Table 1.

\section{Table 1}

Mean and Standard Deviation of Attention Accuracy and Reaction Time

\begin{tabular}{|c|c|c|c|c|c|c|c|c|}
\hline & \multicolumn{4}{|c|}{ Accuracy } & \multicolumn{4}{|c|}{ Reaction time (ms) } \\
\hline & \multicolumn{2}{|c|}{$5 \mathrm{P}$} & \multicolumn{2}{|c|}{$5 \mathrm{E}$} & \multicolumn{2}{|c|}{$5 \mathrm{P}$} & \multicolumn{2}{|c|}{$5 \mathrm{E}$} \\
\hline & $M$ & $S D$ & $M$ & $S D$ & $M$ & $S D$ & $M$ & $S D$ \\
\hline \multicolumn{9}{|l|}{ sr- sound } \\
\hline Pretest & 25.053 & 5.204 & 24.316 & 7.718 & 594.755 & 55.496 & 599.268 & 44.439 \\
\hline Post test & 36.395 & 7.737 & 24.974 & 8.049 & 482.085 & 55.976 & 571.749 & 86.506 \\
\hline \multicolumn{9}{|l|}{ sustain- sound } \\
\hline Pretest & 33.711 & 5.067 & 33.158 & 6.570 & 664.374 & 111.691 & 660.586 & 104.069 \\
\hline Post test & 41.605 & 5.269 & 33.921 & 6.768 & 520.799 & 84.923 & 640.763 & 96.203 \\
\hline \multicolumn{9}{|c|}{ select-ch- sound } \\
\hline Pretest & 32.132 & 4.616 & 31.158 & 5.455 & 686.647 & 77.880 & 683.262 & 78.478 \\
\hline Post test & 40.289 & 4.145 & 31.974 & 7.514 & 561.815 & 91.354 & 668.373 & 77.268 \\
\hline \multicolumn{9}{|l|}{ sr-letter Thai } \\
\hline Pretest & 32.763 & 5.405 & 31.553 & 5.736 & 495.308 & 60.986 & 507.804 & 57.618 \\
\hline Post test & 43.632 & 3.635 & 35.395 & 7.332 & 389.013 & 61.495 & 481.201 & 57.261 \\
\hline \multicolumn{9}{|c|}{ focus- letter Thai } \\
\hline Pretest & 33.132 & 5.878 & 32.842 & 6.171 & 631.731 & 40.042 & 624.235 & 62.551 \\
\hline Post test & 41.105 & 3.415 & 33.921 & 6.716 & 493.297 & 47.571 & 589.394 & 64.879 \\
\hline \multicolumn{9}{|l|}{ Sust- letter Thai } \\
\hline Pretest & 32.526 & 5.254 & 32.816 & 5.899 & 633.261 & 62.160 & 639.982 & 102.993 \\
\hline Post test & 43.053 & 4.526 & 33.947 & 6.802 & 473.871 & 48.152 & 601.952 & 106.098 \\
\hline \multicolumn{9}{|c|}{ D20-select-ch-letter Thai } \\
\hline Pretest & 31.421 & 4.440 & 30.105 & 5.422 & 578.026 & 54.917 & 600.573 & 87.391 \\
\hline Post test & 42.868 & 4.160 & 33.079 & 6.984 & 437.032 & 51.262 & 573.335 & 91.965 \\
\hline
\end{tabular}

(continued) 


\begin{tabular}{|c|c|c|c|c|c|c|c|c|}
\hline & \multicolumn{4}{|c|}{ Accuracy } & \multicolumn{4}{|c|}{ Reaction time (ms) } \\
\hline & \multicolumn{2}{|c|}{$5 \mathrm{P}$} & \multicolumn{2}{|c|}{$5 \mathrm{E}$} & \multicolumn{2}{|c|}{$5 \mathrm{P}$} & \multicolumn{2}{|c|}{$5 \mathrm{E}$} \\
\hline & $M$ & $S D$ & $M$ & $S D$ & $M$ & $S D$ & $M$ & $S D$ \\
\hline \multicolumn{9}{|c|}{ E21-select-ch- letter Thai } \\
\hline Pretest & 32.105 & 4.305 & 31.605 & 6.335 & 684.662 & 40.504 & 681.377 & 50.838 \\
\hline Post test & 44.105 & 3.578 & 34.763 & 7.463 & 550.406 & 54.367 & 634.817 & 65.646 \\
\hline \multicolumn{9}{|l|}{ sr-dot } \\
\hline Pretest & 29.158 & 5.123 & 27.763 & 7.205 & 664.971 & 48.504 & 661.216 & 60.778 \\
\hline Post test & 39.737 & 8.186 & 28.211 & 7.451 & 528.974 & 70.504 & 637.026 & 61.763 \\
\hline \multicolumn{9}{|l|}{ Focus dot } \\
\hline Pretest & 34.816 & 5.746 & 34.053 & 6.217 & 612.131 & 76.785 & 618.576 & 113.361 \\
\hline Post test & 42.895 & 4.459 & 35.500 & 6.612 & 461.056 & 70.591 & 578.824 & 115.773 \\
\hline \multicolumn{9}{|l|}{ sustain-dot } \\
\hline Pretest & 33.605 & 5.325 & 33.368 & 6.153 & 659.499 & 74.308 & 643.786 & 100.054 \\
\hline Post test & 44.395 & 3.817 & 34.658 & 7.455 & 478.424 & 44.266 & 625.556 & 101.350 \\
\hline \multicolumn{9}{|c|}{ D20-select-ch- dot } \\
\hline Pretest & 30.211 & 4.622 & 29.447 & 5.922 & 691.543 & 89.709 & 695.357 & 99.057 \\
\hline Post test & 42.289 & 3.904 & 30.421 & 8.046 & 529.044 & 76.005 & 679.056 & 98.575 \\
\hline \multicolumn{9}{|c|}{ E21-select-ch- dot } \\
\hline Pretest & 30.053 & 5.986 & 30.184 & 6.837 & 726.578 & 100.396 & 710.023 & 101.166 \\
\hline Post test & 41.026 & 7.235 & 34.737 & 6.429 & 552.280 & 77.848 & 687.995 & 101.110 \\
\hline \multicolumn{9}{|l|}{ series Thai letter } \\
\hline Pretest & 33.289 & 4.849 & 33.500 & 5.622 & 659.147 & 77.191 & 664.826 & 100.047 \\
\hline Post test & 44.842 & 3.381 & 35.395 & 7.157 & 523.400 & 81.249 & 656.875 & 105.232 \\
\hline
\end{tabular}

\section{Multivariate Test}

On the aspect of attention accuracy, all of the multivariate tests (Wilks' lambda) were found to be significant. This seems to suggest that the instruction models had significantly influenced attention accuracy at a 0.05 significance level $(F(14,61)=4.124$, $\mathrm{p}=0.000$ ) and could explain the variance of 48.6 percent of attention accuracy $\left(\boldsymbol{y}_{p}^{2}=0.486\right)$. Reaction time had significantly influenced attention accuracy as it showed a 0.05 significance level $(\mathrm{F}(14,61)=38.027, \mathrm{p}=0.000)$ and could explain the variance of 89.7 percent of attention accuracy $\left(\boldsymbol{\eta}_{p}^{2}=0.897\right)$. Moreover, the instruction models had significantly interacted with reaction time at a 0.05 significance level $(\mathrm{F}(14,61)=12.171, \mathrm{p}=0.000)$ and could explain the variance of 73.6 percent of attention accuracy $\left(\boldsymbol{y}_{p}^{2}=0.736\right)$.

For the reaction time of attention, all of the multivariate tests (Wilks' lambda) were significant. This seems to suggest that the instruction models had significantly influenced the reaction time of 
attention at a 0.05 significance level $(F(14,61)=7.122, \mathrm{p}=0.000)$ and could explain the variance of 62.0 percent of attention reaction time $\left(\boldsymbol{y}_{p}^{2}=0.620\right)$. Reaction time was found to be significantly influenced as the reaction time of attention was at a 0.05 significance level $(\mathrm{F}(14,61)=165.003, \mathrm{p}=0.000)$ and could explain the variance of 97.4 percent of attention speed $\left(\boldsymbol{y}_{p}^{2}=0.974\right)$. Moreover, the instruction models had significantly impacted reaction time at a 0.05 significance level $(\mathrm{F}(14,61)=82.127, \mathrm{p}=0.000)$ and could explain the variance of 95.0 percent of reaction time of attention $\left(\boldsymbol{y}_{p}^{2}=0.950\right)$.

The multivariate test informed the significance of at least one mean pairing, thus the individual comparison of the observed mean difference were conducted by the univariate ANOVAs. The univariate tests showed significant interaction effect for all attention measures on both accuracy and reaction. Students in the experimental group performed better with regard to attention accuracy and reacted with lower reaction time than students in the control group.

\section{Findings on Working Memory}

Working memory was also measured based on accuracy and reaction time. The mean score and standard deviation of accuracy and reaction time measured by each working memory tasks between experimental group and control group was shown in Table 2.

Table 2

Mean and Standard Deviation of Working Memory Accuracy and Reaction Time

\begin{tabular}{|c|c|c|c|c|c|c|c|c|}
\hline & \multicolumn{4}{|c|}{ Accuracy } & \multicolumn{4}{|c|}{ Reaction time (ms) } \\
\hline & \multicolumn{2}{|c|}{$5 \mathrm{P}$} & \multicolumn{2}{|c|}{$5 \mathrm{E}$} & \multicolumn{2}{|c|}{$5 \mathrm{P}$} & \multicolumn{2}{|c|}{$5 \mathrm{E}$} \\
\hline & $M$ & $S D$ & $M$ & $S D$ & $M$ & $S D$ & $M$ & $S D$ \\
\hline \multicolumn{9}{|l|}{ Stroop Thai } \\
\hline Pretest & 32.526 & 3.847 & 32.000 & 5.895 & 622.741 & 57.090 & 618.001 & 45.897 \\
\hline Post test & 40.263 & 6.241 & 32.921 & 5.916 & 456.877 & 51.217 & 571.433 & 95.376 \\
\hline \multicolumn{9}{|l|}{ flanker- arrow } \\
\hline Pretest & 24.158 & 2.563 & 23.789 & 2.303 & 640.801 & 25.415 & 649.095 & 53.649 \\
\hline Post test & 41.026 & 5.514 & 26.605 & 4.762 & 501.561 & 34.118 & 594.643 & 53.649 \\
\hline
\end{tabular}




\begin{tabular}{|c|c|c|c|c|c|c|c|c|}
\hline & \multicolumn{4}{|c|}{ Accuracy } & \multicolumn{4}{|c|}{ Reaction time (ms) } \\
\hline & \multicolumn{2}{|c|}{$5 \mathrm{P}$} & \multicolumn{2}{|c|}{$5 \mathrm{E}$} & \multicolumn{2}{|c|}{$5 \mathrm{P}$} & \multicolumn{2}{|c|}{$5 \mathrm{E}$} \\
\hline & $M$ & $S D$ & $M$ & $S D$ & $M$ & $S D$ & $M$ & $S D$ \\
\hline \multicolumn{9}{|l|}{ odd-even } \\
\hline Pretest & 25.553 & 3.002 & 24.737 & 4.131 & 667.000 & 30.582 & 684.675 & 61.018 \\
\hline Post test & 39.289 & 6.036 & 31.658 & 5.951 & 471.771 & 58.787 & 600.185 & 88.903 \\
\hline \multicolumn{9}{|l|}{ vowel-consonant } \\
\hline Pretest & 27.289 & 5.245 & 26.526 & 7.880 & 628.705 & 53.405 & 596.292 & 95.638 \\
\hline Post test & 36.816 & 5.357 & 26.868 & 7.854 & 384.008 & 64.156 & 559.395 & 72.089 \\
\hline \multicolumn{9}{|c|}{ SW-Th Letter Number } \\
\hline Pretest & 28.026 & 5.284 & 27.026 & 7.295 & 681.388 & 37.048 & 643.261 & 73.864 \\
\hline Post test & 34.158 & 7.387 & 27.079 & 7.269 & 413.095 & 67.187 & 582.905 & 73.864 \\
\hline \multicolumn{9}{|l|}{ left-right } \\
\hline Pretest & 27.947 & 6.543 & 28.342 & 6.803 & 523.735 & 57.852 & 528.471 & 45.932 \\
\hline Post test & 36.158 & 5.548 & 28.684 & 6.535 & 375.902 & 59.325 & 480.214 & 44.050 \\
\hline \multicolumn{9}{|l|}{ up-down } \\
\hline Pretest & 28.132 & 4.604 & 27.605 & 6.820 & 548.204 & 49.749 & 566.614 & 44.656 \\
\hline Post test & 37.763 & 5.504 & 28.526 & 7.262 & 408.349 & 66.289 & 511.220 & 43.722 \\
\hline \multicolumn{9}{|c|}{ SW-up-down-left-right } \\
\hline Pretest & 24.763 & 4.739 & 24.211 & 6.839 & 680.876 & 38.726 & 663.196 & 50.880 \\
\hline Post test & 36.579 & 5.626 & 24.553 & 6.575 & 443.646 & 93.865 & 611.819 & 50.107 \\
\hline \multicolumn{9}{|l|}{ Thai word span } \\
\hline Pretest & 23.816 & 4.684 & 23.526 & 6.509 & 699.139 & 31.826 & 678.121 & 45.805 \\
\hline Post test & 35.868 & 4.732 & 24.842 & 7.354 & 484.550 & 90.151 & 636.946 & 57.073 \\
\hline \multicolumn{9}{|l|}{ number updating } \\
\hline Pretest & 3.579 & 2.164 & 3.316 & 2.440 & 868.768 & 60.170 & 825.952 & 108.241 \\
\hline Post test & 6.553 & 2.089 & 3.342 & 2.209 & 539.876 & 51.405 & 731.723 & 155.719 \\
\hline \multicolumn{9}{|l|}{ 0-back } \\
\hline Pretest & 2.263 & 1.639 & 2.395 & 1.480 & 937.035 & 19.689 & 949.017 & 24.730 \\
\hline Post test & 5.316 & 1.435 & 3.053 & 1.627 & 832.066 & 26.348 & 892.092 & 30.689 \\
\hline \multicolumn{9}{|l|}{ 1-back } \\
\hline Pretest & 1.789 & 1.436 & 1.500 & 0.980 & 801.457 & 69.489 & 813.782 & 62.759 \\
\hline Post test & 3.605 & 1.980 & 1.579 & 1.056 & 684.378 & 54.318 & 800.204 & 62.536 \\
\hline \multicolumn{9}{|l|}{ 2-back } \\
\hline Pretest & 1.000 & 1.294 & 0.974 & 0.822 & 907.953 & 72.864 & 888.170 & 77.123 \\
\hline Post test & 3.500 & 1.689 & 1.605 & 1.028 & 731.810 & 43.397 & 882.219 & 79.679 \\
\hline
\end{tabular}

\section{Multivariate Test}

For working memory accuracy, all of the multivariate tests (Wilks' lambda) were significant. This suggests that the instruction models have significantly influenced the working memory accuracy at a 
0.05 significance level $(\mathrm{F}(13,62)=11.758, \mathrm{p}=0.000)$ and can explain the variance of 71.1 percent of the working memory accuracy $\left(\boldsymbol{y}_{p}^{2}=0.711\right)$ Times have significantly influenced the working memory ackuracy at a 0.05 significance level $(\mathrm{F}(13,62)=105.086, \mathrm{p}=0.000)$ and can explain the variance of 95.7 percent of the working memory accuracy $\left(\boldsymbol{y}_{p}^{2}=0.957\right)$. Moreover, the instruction models have significantly interacted with times at a 0.05 significance level $(\mathrm{F}(13,62)=74.277, \mathrm{p}=0.000)$ and can explain the variance of 95.0 percent of the working memory accuracy $\left(\boldsymbol{y}_{p}^{2}=0.940\right)$.

For reaction time of working memory, all of the multivariate tests (Wilks' lambda) were significant. This suggests that the instruction models have significantly influenced the reaction time of working memory at a 0.05 significance level $(F(13,17)=4.845, p=0.002)$ and can explain the variance of 78.7 percent of the reaction time of working memory $\left(\boldsymbol{y}_{p}^{2}=0.787\right)$. Times have significantly influenced the reaction time of working memory at a 0.05 significance level $(\mathrm{F}(13,17)=78.832, \mathrm{p}=0.000)$ and can explain the variance of 98.4 percent of the reaction time of working memory $\left(\boldsymbol{y}_{p}^{2}=0.984\right)$. Moreover, the instruction models have significantly interacted with times at a 0.05 significance level $(F(13,17)=25.677, \mathrm{p}=0.000)$ and can explain the variance of 95.2 percent of the reaction time of working memory $\left(\boldsymbol{y}_{p}^{2}=0.952\right)$.

The multivariate test informs the significance of at least one mean pairing, thus the individual comparisons of the observed mean difference were conducted by the univariate ANOVAs. The univariate tests showed significant interaction effect for all working memory measures in terms of both accuracy and reaction time. Students in the experimental group performed with better accuracy and reacted with lower reaction time than students in control group.

\section{Findings on Mood}

Mood was measured in terms of the following three categories: alertness, calmness, and contentedness. The mean score and standard deviation of alertness, calmness, and contentedness are as shown in Table 3. 
Table 3

Mean and Standard Deviation of Alertness, Calmness, and Contentedness

\begin{tabular}{ccccc}
\hline & \multicolumn{5}{c}{ Mood } \\
\cline { 2 - 5 } & \multicolumn{3}{c}{$5 \mathrm{P}$} & \multicolumn{3}{c}{$5 \mathrm{E}$} \\
\cline { 2 - 5 } & & & & \\
& \multicolumn{1}{c}{$M$} & & & \\
alertness & 60.263 & 10.659 & 59.342 & 9.743 \\
Pretest & 70.895 & 9.723 & 62.026 & 10.683 \\
Post test & & & & \\
calmness & 12.395 & 2.212 & 12.263 & 2.533 \\
Pretest & 15.553 & 2.226 & 13.474 & 2.938 \\
Post test & & & & \\
contentedness & 39.263 & 6.395 & 39.289 & 6.116 \\
Pretest & 43.421 & 5.495 & 39.474 & 7.277 \\
Post test & & & & \\
\hline
\end{tabular}

\section{Multivariate Test}

All of the multivariate tests (Wilks' lambda) were significant. The instruction models significantly influenced mood at a 0.05 significance level $(\mathrm{F}(3,72)=2.620, \mathrm{p}=0.047)$ and can explain the variance of 9.8 percent of mood $(=0.0989$. Times significantly influenced mood at a 0.05 significance level $(F(3,72)=31.128$, $\mathrm{p}=0.000$ ) and can explain the variance of 56.5 percent of $\operatorname{mood}\left(\boldsymbol{y}_{p}^{2}=0.565\right)$. Moreover, instruction models significantly interacted with times at a 0.05 significance level $(F(3,72)=9.686$, $\mathrm{p}=0.000$ ) and can explain the variance of 28.8 percent of mood $\left(\boldsymbol{\eta}_{p}^{2}=0.288\right)$.

The multivariate test informs the significance of at least one mean pairing, thus the individual comparison of the observed mean difference was carried out using the univariate ANOVA. The univariate tests showed significant interaction effect for alertness, calmness, and contentedness. Students in the experimental group had better mood than students in the control group. 


\section{Summary on the Group Differences}

In order to achieve the main aim of this research, the researchers examined all of the above data obtained via tables and have been able to come to some general conclusions. Based on the statistical results, we can conclude that there are significant differences between the experimental and control groups. The results revealed that the learners in the experimental group outperformed the learners of the control group, as indicated in Table 4 below.

As indicated by Tinsley and Brown (2000), Wilks' lambda values close to 0 indicate that almost all of the variability in the discriminator variables is due to group differences, and Wilks' lambda values close to 1 indicate that almost all of the variability in the discriminator variables is due to within group differences (differences between cases in each group). Therefore, the smaller the Wilks' lambda value or the greater value of partial eta-square, the greater the differences between groups. In addition, the lower the Wilks' lambda, the more the given effect contributes to the model. In light of the above statistical observations, the researchers came to the conclusion that the two instructional models had made a difference to the learning outcomes of Grade 9 students, particularly in working memory, followed by attention. However, mood was not greatly different between the two groups.

Table 4

Wilks' Lambda and Partial Eta-Square of Dependent Variables

\begin{tabular}{|c|c|c|c|c|c|c|}
\hline \multirow[t]{3}{*}{ Dependent variables } & \multirow{2}{*}{\multicolumn{2}{|c|}{ Between group }} & \multicolumn{4}{|c|}{ Within group } \\
\hline & & & \multicolumn{2}{|c|}{ model } & \multicolumn{2}{|c|}{ model $\mathrm{x}$ time } \\
\hline & $\lambda$ & $\boldsymbol{\eta}_{p}^{2}$ & $\lambda$ & $\boldsymbol{\eta}_{p}^{2}$ & $\lambda$ & $\boldsymbol{\eta}_{p}^{2}$ \\
\hline Attention accuracy & 0.514 & 0.486 & 0.103 & 0.897 & 0.264 & 0.736 \\
\hline Reaction time of attention & 0.380 & 0.620 & 0.026 & 0.974 & 0.050 & 0.950 \\
\hline Working memory accuracy & 0.289 & 0.711 & 0.043 & 0.957 & 0.060 & 0.940 \\
\hline Reaction time of working memory & 0.213 & 0.787 & 0.016 & 0.984 & 0.048 & 0.952 \\
\hline Mood & 0.902 & 0.098 & 0.435 & 0.565 & 0.712 & 0.288 \\
\hline
\end{tabular}




\section{DISCUSSION}

The findings of this study have revealed a greater understanding of the causal mechanism of the neurocognitive-based model (5P) on the improvement of learner attention, working memory, and mood and have the potential of making a significant contribution to education. The researchers have successfully explored how the mechanisms of learning and development relate to group differences in educational attainment and thus, educational intervention can be optimized.

The results of this study have supported the claim of effectiveness of the neurocognitive-based instructional model (5P) in enhancing learner attention, working memory, and mood. As a result of the robust evidence provided in this study, it is hoped that the neurocognitive-based instructional model (5P) will be applied in improving learner outcomes in the future.

The findings of this study imply that current teachers should focus on educational neuroscience to design an instructional model in order to enhance and improve the learning outcomes of their students. In this regard, teachers are encouraged to utilize the neurocognitivebased model (5P) since it has been found to be capable of developing the attention, working memory, and mood of students. Moreover, this implies that by emphasizing the development of attention, working memory, and mood it will be possible to enhance students' ability to embed their knowledge in the long-term memory (Anderson, 2009; Merikle, 2000; Hardiman, 2012). Consequently, teachers should provide sufficient opportunities for students to develop these domains. The results of this study are similar to the findings in the studies by Anderson (2009), Baddeley (2012), and Hardiman (2012).

Ultimately, the linking of neurocognitive learning theory and education is about the creation of something new, either a new discipline or new concepts and understanding that can advance work on both sides of this disciplinary boundary. This can be in terms of more targeted research in neurocognitive-based learning or more effective use of this research in developing classroom practices in education. 
In conclusion, there is a revolution imminent in education. These findings concerning the influence of cognitive neuroscience, in particular, will have profound implications for education, eventually leading to innovations in practice and policy. Irrespective of their scientific value, the learner brain findings are powerful for education only insofar as they have helped to change our perspective of how learning and development happen. It is suggested that teachers work together to understand and practise the new ways of development that have practical implications for the design of learning instructions.

\section{ACKNOWLEDGEMENT}

This work was supported by the Higher Education Research Promotion and National Research University Project of Thailand, Office of the Higher Education Commission, through the Cluster of Research to Enhance the Quality of Basic Education.

\section{REFERENCES}

Anderson, O. R. (2009). Neurocognitive theory and constructivism in science education: A review of neurobiological, cognitive and cultural perspectives. Brunei International Journal of Science \& Mathematics Education, 1(1), 1-32.

Baddeley, A. (2012). Working memory: Theories, models, and controversies. Annual Review of Psychology, 63(1), 1-29. Retrieved from http://doi.org/10.1146/annurev-psych-120710100422

Baddeley, A.D. \& Hitch, G.J. (1974). Working memory. The psychology of learning and motivation, 8, 47-89.

Brandoni, C. \& Anderson, O. R. (2009). A new neurocognitive model for assessing divergent thinking: Applicability, evidence of reliability, and implications for educational theory and practice. Creativity Research Journal, 21(4), 326-337. Retrieved from http://doi.org/10.1080/10400410903297352.

Bunterm, T., Ketchatturat, J., Samranjai, J., Methaneethorn, J., Wattanathorn, J., Muchimapura, S., Wannanon, P., Uopasai, S., Srikoon, S., \& Werachairatana, S. (2015). The development of cognitive function battery test: Thai version. National Research Council of Thailand: Thailand. 
Bunterm, T., Lee, K., Ng, L. K. J., Srikoon, S., Vangpoomyai, P., Rattanavongsa, J., \& Rachahoon, G. (2014). Do different levels of inquiry lead to different learning outcomes? A comparison between guided and structured inquiry. International Journal of Science Education, 36(12), 19371959, doi: 10.1080/09500693.2014.886347.

Cowan, N. (2012). Working memory: The seat of learning and comprehension. In S. D. Sala \& Anderson, M., Neuroscience in education: The good, the bad and the ugly (Chapter 1). doi:10.1093/acprof:oso/9780199600496.001.001. Great Britain: Oxford University Press.

De Carolis, B. \& Ferilli, S. (2014). Towards learning relations between user daily routines and mood. CEUR Workshop Proceedings, 64-71.

Denning, P.J. (2013). The profession of IT moods, wicked problems, and learning. Communications of the ACM, 56(3), 30-32. Retrieved from http://doi.org/10.1145/2428556.2428566.

Everitt, B. S. \& Dunn, G. (1991). Applied multivariate data analysis (2nd ed.). London: Edward Arnold.

Ferry, B., Roozendaal, B., \& McGaugh, J. L. (1999). Role of norepinephrine in mediating stress hormone regulation of long-term memory storage: A critical involvement of the amygdale. Biological Psychiatry, 46(9), 1140-1152.

Gazzaniga, M. S., Ivry, R. B. \& Mangun, G. R. (2009). Cognitive neuroscience: The biology of the mind ( $3^{\text {rd }}$ ed.). New York, NY: Norton.

Goswami, U. (2008). Cognitive development: The learning brain. Hove: Psychology Press.

Goswami, U., \& Szucs, D. (2010). Educational neuroscience: Developmental mechanisms: Towards a conceptual framework. Neurolmage, 57(2011), 651-658.

Hair, J. F., Black, W. C., Babin, B. J., Anderson, R. E., \& Tatham, R.

L. (2006). Multivariate data analysis (6th ed.). USA: Pearson Education.

Hardiman, M. (2012). The brain-targeted teaching model for $21^{s t}$ century schools. Corwin: A Sage Company.

Institute for the Promotion of Teaching Science and Technology (2012). Science measurement and assessment. Bangkok: V. Print Co., Ltd. 
Jacob, C. \& Silvanto, J. (2015). How is working memory content consciously experienced? The 'conscious copy' model of WM introspection. Neuroscience and Biobehavioral Reviews, 55, 510-519. Retrieved from http://doi.org/10.1016/j.neubiorev. 2015.06.003

Joyce, B., Weil, M. \& Calhoun, E. (2015). Models of teaching $\left(9^{\text {th }}\right.$ ed.). USA: Pearson Education.

Loaiza, V. M., \& McCabe, D. P. (2013). The influence of aging on attentional refreshing and articulatory rehearsal during working memory on later episodic memory performance. Aging, Neuropsychology, and Cognition, 20(4), 471-493. Retrieved from http://doi.org/10.1080/13825585.2012.738289.

Mayer, J. S., Kim, J. \& Park, S. (2011). Enhancing visual working memory encoding: The role of target novelty. Visual Cognition, 19(7), 863-885. Retrieved from http://doi.org/10.1 080/13506285.2011.594459

Meltzer, L. (2010). Promoting executive function in the classroom. New York: The Guilford Press.

Merikle, P. (2000). Consciousness and unconsciousness: Processes. In A. E. Kazdin (Ed.), Encyclopedia of Psychology. (Vol. 2, pp. 272-275). Washington, DC: American Psychological Association.

Newton, D. P. (2013). Moods, emotions and creative thinking: A framework for teaching. Thinking Skills and Creativity, 8(1), 34-44. Retrieved from http://doi.org/10.1016/j.tsc.2012.05. 006

Rao, R. P. N. (2003). Attention, models of. In L. Nadel (Ed.), Encyclopedia of Cognitive Science. (Vol.1, pp. 231-237). London: Nature Publishing Group.

Srikoon, S., Bunterm, T., Samranjai, J., \& Wattanathorn, J. (2014). Research synthesis of research-based learning for education in Thailand. Procedia - Social and Behavioral Sciences (Vol. 2, pp, 913 - 917).

Srikoon, S. (2015). Development of educational neuroscience and research-based instructional model (Unpublished doctoral dissertation). Khon Kaen University: Thailand.

Sanchez-Torres, A. M., Rosa Elosua, M, Lorente-Omenaca, R, Moreno-Izco, L., \& Cuesta, M. J. (2015). A comparative study of the working memory multicomponent model in psychosis and healthy control. Comprehensive Psychiatry, 61, 97-105. 
Sieb, R. A. (1990). A brain mechanism for attention. Medical Hypotheses, 33(3), 145-153.

Sternberg, R.J. (2012). Cognition (6th ed.). Canada: Wadsworth CENGAGE Learning.

Tinsley, H. E. A., \& Brown, S. D. (2000). Handbook of applied multivariate statistics and mathematical modelling. Missouri: Elsevier Inc.

Yang, H. Y., \& Chang, C. C. (2015). The effect of attention cueing on science text learning. Tech Know Learn. doi: 10.1007/ s10758-015-9264-6. 